\title{
Removal of Directs Dyes from Wastewater by Cotton Fiber Waste
} Nacera Ouslimani and Mohamed Zine Messaoud Boureghda*

Laboratory of Food Technology, M'hamed Bougara University, Boumerdes, Algeria

\begin{abstract}
Environment protection is a precondition for sustained growth and a better quality of life for all peoples on earth Aqueous industrial effluents are the main sources of pollution. Among the compounds of these effluents, dyes are particularly resistant to discoloration by conventional methods, and discharges present many problems that must be supported.

Synthetic dyes are used in industrials sectors; especially in the textile, industry. There is a certain selectivity of raw cotton fibers for the different types of dyes, depending on the chemical structure of the dyes. We note that this affinity is very high for direct dyes and decreases for reactive dyes and pigment dyes.

This study focuses on the elimination of direct dyes wastewater from the textile industry, by their adsorption on waste very adsorbent cotton fibers, the removal rate greater than $75 \%$ for the three types of direct dyes used, a mathematical of the adsorption isotherms of and their kinetics of adsorption was made and shows the mathematical models of adsorption curves, it shows that the direct dye red216 adsorbs very easily and the saturation is obtained after $30 \mathrm{mn}$ and the direct yellow 4 dye s' adsorbs regularly and reaches the saturation $100 \mathrm{~mm}$, which shows that the adsorption is done according to the spatial structure of the dye and the porosity of the cotton this technique is interesting, it allows to recover adsorbate cotton as raw material for several uses and at very low cost.
\end{abstract}

Keywords: Cotton directs dyes; Adsorption reuse wastewater; Textile; Kinetics equilibrium; Kinetics thermodynamic

\section{Introduction}

In Algeria, sustainable development imperatively requires the protection of the environment and sustained economic growth based on cleaner technology, which must be concerned by the quality of life of citizens. Accordingly, must be aware of adverse effects related to environmental hazards generated by manufacturing waste. Industrial wastewater discharges are the main sources of pollution receptors environments. The flows from many processes are very varied and give a complex final effluent; this complexity depends on several factors such as the type and nature of the raw material, finished product, engineering, chemicals and additives used.

The demands of health-conscious citizens and the protection of their environment, so that the liquid discharges of textile industries comply with the regulations, which is very strict in this area; has forced managers to take adequate measures to meet the expectations of civil society. Unfortunately, the complex synthetic dyes used make discoloration difficult [1] the colorants are, largely, very soluble in aqueous solutions and their elimination presents a formidable challenge [2]. Although the dyes are only a small proportion of the total volume of industrial liquid waste, they are not easily removed, biologically, because their chemical structure is very complex.

Every year in the world 7105 tons of dyes are consumed consisting of 10.000 different types of dyes, the percentage of dye found in the rejects at $15 \%$ following the dyeing process [3]. This massive influx of organic chemicals into rivers poses enormous problems, including visual pollution, eutrophication, aquatic biodiversity and the environmental health of the peoples of the region [4]. It also represents an increasing environmental danger due to their refractory carcinogenic nature $[5,6]$. The reduction of the dye concentration in wastewater to environmentally acceptable values is an absolute necessity. Among several chemical and physical methods are used, but adsorption remains the most effective, as shown by the indicators: cost and performance [7]. Several conventional techniques of discoloration used industrially (automotive, chemicals, paper and textiles) have shown their limits [8] because the treated waste arising in the nature of many problems to solve; for the textile industry, the affinity between the fibers and the dyes vary depending on the chemical structure of dyes and the type of materials to which they are applied [9]. It is often observed that during the dyeing operation, from $15 \%$ to $20 \%$ of the sulfur dyes and sometimes up to $40 \%$ of the reactive dyes are found in the effluent.

The affinity of the dye for the fiber is particularly developed, which have an acidic character or basic accented. These dye-specific characteristics increase their persistence in the environment and make reluctant to biodegraded [10].

The direct dyes contain or are capable of forming positive or negative charges electrostatically attracted loads of fiber. They are distinguished by their affinity for cellulosic fibers without application of mordant, linked to the plane structure of their molecule [11].

We must also emphasize the adverse effects on the health of wildlife and indirectly human health, because many dyes used found in lakes and rivers are toxic. Carcinogenic effects have been diagnosed in mammals following metabolites resulting from the enzymatic digestion of coloring molecules. The purpose of this study is to remove direct dyes contained in the wastewater, using as adsorbent waste cotton fibers. This technique has a double advantageous alternative both economically and environmentally, the first is the reuse of residual fibers after adsorption, as a raw material for the manufacture of alternative products (pillows, mattress cushion), the second is the on-site treatment of wastewater. The

${ }^{*}$ Corresponding author: Mohamed Zine Messaoud Boureghda, Laboratory of Food Technology, M'hamed Bougara University, Boumerdes 35000, Algeria, Tel: +0540346828; E-mail: boureghdamed@yahoo.fr

Received March 29, 2018; Accepted April 15, 2018; Published April 22, 2018

Citation: Ouslimani N, Boureghda MZM (2018) Removal of Directs Dyes from Wastewater by Cotton Fiber Waste. Int J Waste Resour 8: 330. doi: 10.4172/22525211.1000330

Copyright: @ 2018 Ouslimani N, et al. This is an open-access article distributed under the terms of the Creative Commons Attribution License, which permits unrestricted use, distribution, and reproduction in any medium, provided the original author and source are credited. 
color is a very important physiological factor in the pollution $[12,13]$ these are the most typical in the textile finishing industrial emissions. Colored effluents discharged without proper treatment generate a considerable number of changes in the receiving environment [14]. These effluents are characterized by, alkaline $\mathrm{pH}$, dark brown color, unpleasant odour, high biological and chemical oxygen demand, total dissolved solids and a mixture of organic and inorganic pollutants.

Wherein the proportion of biodegradable materials can be very low [13].The available methods for bleaching effluent depend on the state of the dyes used (soluble or insoluble). For insoluble dyes, used techniques are generally mechanical (decantation, flotation, centrifugation, with or without flocculation). Regarding soluble dyes, other methods are used: Dyestuffs and pigments are reported to be carcinogenic and highly toxic to living beings, this necessitates the removal of dye from wastewater. Biological processes are ineffective to remove color, because groups of atoms responsible for color are the chromophoric groups $(-\mathrm{C}=\mathrm{C}-\mathrm{C}=$ $\mathrm{C}-;-\mathrm{C}=\mathrm{N}-;-\mathrm{N}=\mathrm{N}-;-\mathrm{C}=\mathrm{C}-\mathrm{C}=\mathrm{O}$ and the auxochromic groups: $\mathrm{NH}_{2},-\mathrm{OH},-\mathrm{O}-\mathrm{CH} 3 ;-\mathrm{Br}[12,15,16]$ in the textile industry, conventional methods of color removal, such as: coagulation, flocculation are often used [7,17]; as well as other adsorbents such as commercial activated carbon (CAC), clays and clay minerals [18], sawdust, bagasse, orange peel, roots have also been used, but the cost of these processes must be studied . in the textile industry, conventional methods of color removal, such as: coagulation, flocculation are often used [7,17]; as well as other adsorbents such as commercial activated carbon (CAC), clays an clay minerals [18], sawdust, bagasse, orange peel, roots, have also been used, but the cost of these processes must be studied $[19,20]$.

\section{Materials and Methods}

\section{Adsorbate}

The direct dyes used in this study are "red 216, blue 186 and yellow $4 "$, as well as a mixture of the three dyes in equal proportions.. The chemical properties of studied dyes are shown in Figure 1 and Table 1 it was collected in the textile factory "DBK, Algeria", directly in large dyeing storage tanks, equilibrium concentrations of the dyes were determined by a UV-visible spectrophotometer "Shimadzu UV 160". The degree of initial fixation of dyes on cloth is 64 to $96 \%$.

\section{Adsorbent}

The choice of cotton is also motivated by The raw cotton contains about $87 \%$ cellulose, but after treatment it rises to $98-99 \%$, it is a very adsorbent material and it has a very high quality hydropyle, it is a material available and inexpensive [21].

These dyes have an affinity for the cellulosic fibers (cotton), the focuses, which intervene in this property, are hydrogen bridges, dipolar forces and hydrophobic interactions, and this is done via the hydroxyl groups of cellulose [22].

During the textile dyeing operation, a fraction of the dye is fixed on the solid fiber phase and the other fraction remains the aqueous phase; at the end of the process, it is the soluble fraction that must be removed [23]

Direct dyes have a linear structure and planar synthesized with sulfonic acid groups to increase their solubility in water, they are particularly valued for dyeing cellulosic fibers (Figure 2), this behavior allows the dye to bind on cellulose chains in cotton fiber, often by intermolecular bonding (including hydrogen).

Direct dyes are also very important in the cellulosic fibers dyeing process: $75 \%$ of total consumption is used for dyeing cotton or viscose

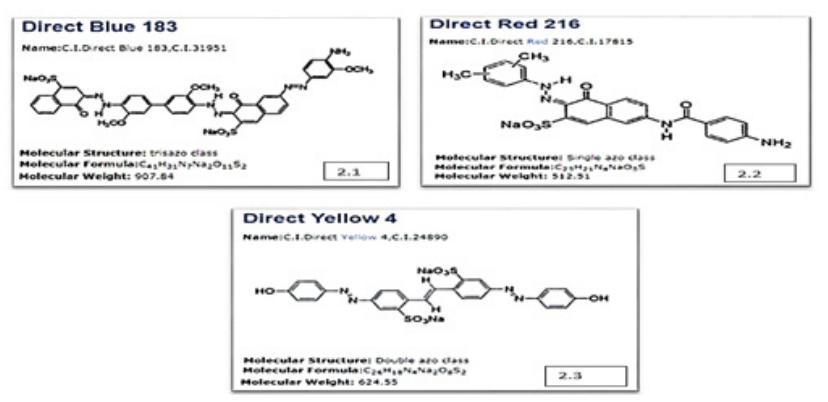

Note: Source : Shaoxing Biying Textile Technology Ltd WWW.biyingdye.com

Figure 1: Chemical formula of dyes.

\begin{tabular}{|c|c|c|c|}
\hline & Blue 183 & Red 216 & Yellow 4 \\
\hline Solubility [g/l] & & & \\
\hline $90^{\circ} \mathrm{C}$ & 40 & 80 & 80 \\
\hline $60^{\circ} \mathrm{C}$ & 30 & 60 & 50 \\
\hline $30^{\circ} \mathrm{C}$ & 30 & 60 & 50 \\
\hline Removal dégrée (\%) & 87 & 99 & 95 \\
\hline Equalizing power & & & \\
\hline $98^{\circ} \mathrm{C} / 208^{\circ} \mathrm{F}$ & médian & good & Very good \\
\hline $130^{\circ} \mathrm{C} / 266^{\circ} \mathrm{F}$ & good & médin & Very good \\
\hline
\end{tabular}

Table 1: Used direct dyes characteristics.

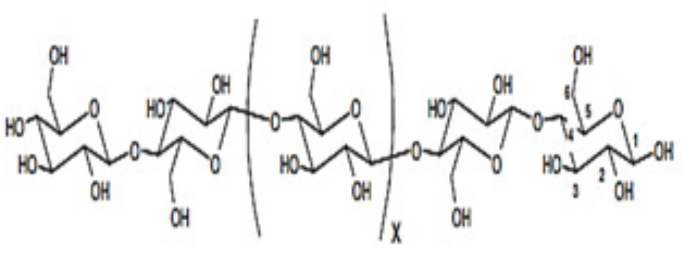

Figure 2: Chemical formula of cotton.

substrates. The specific area of cotton is $10^{-3} \mathrm{~km}^{2} \cdot \mathrm{kg}^{-1}-13,4.10^{-3} \mathrm{~km}^{2}$. $\mathrm{kg}^{-1}[24,25]$.

Dyes that have an aquatic toxicity and/or allergenic effects [26,27]. It is also important to mention here that about 60 to 70 percent of dyes used at present are azo- dyes [28] under reducing conditions, these dyes can produce amines and some of them are carcinogenic)

For our study, we used cotton waste from the textile factory DBK (Algeria). They are recovered at the beginning of the process of manufacture 1 (raw cotton) and after cutting the fabric, in the raw state (Figure 3), among the waste recovered at the unit DBK (carding waste, waste Willo) they contain less impurities, about 18 percent.

\section{Cotton surface structure}

The surface of the structure of cotton, seen under an electronic (microscope dotopon Electronique pratique, 5 MP USB 8), shows that the material has a certain porosity of different sizes, especially mesopores and micropores distributed unequally and which denotes its capacity to adsorb medium and large diameter molecules, which facilitates the flattened physical adsorption.

\section{Wastewater characteristics}

Wastewater Analyses were performed on a daily basis of the 


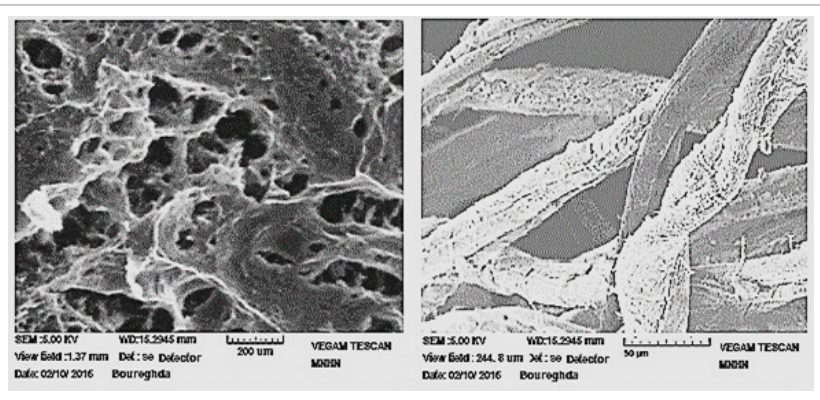

Figure 3: Sampler taking from the study.

pollution control (Table 2). The method used for the effluents treatment in the manufactory. The dye bath has an alkaline $\mathrm{pH}$ (9.95), due to the presence of $\mathrm{Na}_{2} \mathrm{CO}_{3}$, an alkaline agent, in the solution of direct dye. The decrease in the $\mathrm{pH}$ of the stripping solution is due to consumption of the alkali agent during dyeing process. Suspended solids results from used chemicals, high dyes concentrations and fiber waste. We also note that the turbidity is due to a bad dye bath exhaustion and perhaps improper attachment of direct dye and hydrolysis of reactive dyes. This high Chemical Oxygen Demand content is explained by high used concentration of dyes and chemicals.

\section{Procedure}

In bottles of 1 liter of the colored effluent (for each color), a 35\% concentration, we introduced increasing quantitites $0.5,1,1.5,2,2.5$ and 3 grams of waste cotton fibers, the concentrations are given in Table 3. We opted for two approaches: one is adsorption in static batch and the other in stirred batch system and see the influence of agitation on the time and efficiency of the adsorption.

Positions of sampling: Figure 4 shows places of sample taking waste cotton fibers and wastewater.

\section{Results and Discussions}

\section{DBK water dyeing discoloration tests}

The tests were carried out with direct dyes on cotton waste from the same unit. The dyeing is done according to the periodic method with the same recipes as those used on the site. After removing water and the exhaustion of the washing bath, the initial concentration of the dyes is measured by the spectrophotometric method based on the calibration curve previously prepared for each dye.

The adsorbate was raw and in this study, we took into consideration the weight of the adsorbent (waste fiber) and time to exhaustion of the colored solution the experiments were conducted in a batch system.

\section{Adsorption tests}

Influence of contact time and fiber mass on dye adsorption, resting system: The research interest in this step is to determine the mass of the fibers and the wavelength at which the dye adsorption by the adsorbent is reasonable and intéressante. From these results, it should be noted that the rate of It is proportional to the weight of the fiber and the contact time. However, the bleaching phenomenon was stabilized at 120 minutes even if you increase the amount of adsorbent.

We note that the dye kinetics is the same for all colors and their mixture with a saturation of the adsorbent by contact after $120 \mathrm{~min}$. We can say that dyeing wastewater discoloration of direct dyes by cotton fibers is possible since the results are satisfactory. This can be explained by the high affinity of these dyes with these fibers (Figures 5-8).

Influence of agitation on the adsorption time of direct dyes: One of the objects to be achieved in this part is to find the optimum rate of exhaustion of the color as a function of the mass of cotton fiber with a moderate stirring of $25 \mathrm{rpm}$. The results are shown in Figures 9-11.

The results show that the dyes of the removal rates increase proportionally with the increase in the mass of fibers and the stirring time the performance of the adsorption reaches rates ranging between 80 and $90 \%$, and yields are far better than static adsorption.

We observe that a moderate stirring while giving a very good yield, decreases the adsorption time of $30 \mathrm{~min}$ for the direct red dye and has no influence on the other two, this is probably the mode of fixation and the chemical spatial structure of the dye, which seems to say that the adsorption is to a chemical model for red and physical (van der walls forces) for the other two dyes.

\section{Adsorption kinetics}

Several effective mathematical models are used to study the adsorption mechanism and evaluate the adsorption rate and several kinetic models are used to test experimental data [29].To explore diffusion behavior and adsorption resistances, which may result from it, it is necessary to use an intraparticular diffusion model [30].

$$
q t=k_{p} t^{1 / 2}+I
$$

Where, $\mathrm{q}$ and t: quantity "mg" of adsorbate per "g" of adsorbent "t $(\mathrm{mg} / \mathrm{g})$ at time $\mathrm{t}(\mathrm{min})$,

$\mathrm{k}_{\mathrm{p}}$ : the rate constant of the intraparticular diffusion model $(\mathrm{mg} / \mathrm{g}$ $\mathrm{mn} 1 / 2)$,

\section{I: interception.}

The values of "I" gives an idea about the thickness of the boundary layer. In this model, the absorption curve should be linear if the intraparticular diffusion is involved in the adsorption process and if the curves pass through the origin, in this case, the intraparticular diffusion is the step controlling the velocity [31].

If the curves do not pass through the origin which shows some limitation of the adsorption of the boundary layer, and the internal diffusion is not the only limiting factor and there are other kinetic models that control the adsorption rate.

Pseudo-first order equation is generally represented as follows:

$$
\frac{d q}{d t}=k_{1}\left(q_{e-} q_{t}\right)
$$

If " $\mathrm{q}_{\mathrm{e}}$ " is the amount of equilibrium adsorbed dye (mg/g) and "k1" is the equilibrium rate constant, the kinetics of the pseudo-first order reaction $(\mathrm{mn} .1)$, after integration applying the conditions $\left[\mathrm{q}_{\mathrm{t}}=0\right.$ to $\mathrm{t}=0$ and $\mathrm{q}_{\mathrm{t}}=\mathrm{q}_{\mathrm{t}}$ to $\mathrm{t}=\mathrm{t}$ ], then Equation (2) becomes:

$$
\log \left(q_{c-} q_{t}\right)=\log q_{c-} \frac{k 1}{2.303} t
$$

(Equation 3)

The data were applied to the equation of the pseudo-second order is written:

$$
\frac{d q}{d t}=k_{2}\left(q_{c-} q_{t}\right)^{2}
$$

(Equation 4)

Where $\mathrm{k}_{2}$, which is constant for the equilibrium rate $(\mathrm{g} / \mathrm{mg} / \mathrm{min})$, 
Citation: Ouslimani N, Boureghda MZM (2018) Removal of Directs Dyes from Wastewater by Cotton Fiber Waste. Int J Waste Resour 8: 330 . doi: 10.4172/2252-5211.1000330

Page 4 of 8

\begin{tabular}{|c|c|c|c|c|c|c|c|c|c|c|}
\hline \multirow[b]{2}{*}{$\begin{array}{l}\text { Température } \\
\text { (C) }\end{array}$} & \multirow[b]{2}{*}{$\mathbf{Q}_{0}$} & \multicolumn{3}{|c|}{ Langmuir isotherm model } & \multicolumn{3}{|c|}{ Freundlich isotherm model } & \multicolumn{3}{|c|}{ Tempkin isotherm model } \\
\hline & & $\mathbf{K}_{\mathrm{L}}$ & $\mathbf{R}_{\mathrm{L}}$ & $\mathbf{R}_{\mathrm{L}}^{2}$ & $\mathbf{K}_{\mathrm{F}}$ & $\mathbf{n}$ & $\mathbf{R}_{\mathrm{F}}^{2}$ & $\mathbf{K}_{\mathrm{T}}$ & $B_{1}$ & $\mathbf{R}_{\mathrm{T}}^{2}$ \\
\hline \multicolumn{11}{|c|}{ Direct Red 216} \\
\hline 20 & 24.56 & 0.23 & 0.07 & 0.99 & 19.56 & 3.56 & 19.56 & 3.67 & 12.05 & 0.996 \\
\hline 30 & 24.31 & 0.27 & 0.06 & 0.999 & 20.47 & 3.78 & 0.992 & 4.63 & 12.38 & 0.976 \\
\hline 40 & 23.78 & 0.25 & 0.06 & 0.999 & 22.78 & 3.90 & 0.993 & 7.78 & 11.12 & 0.976 \\
\hline 50 & 21.54 & 0.26 & 0.05 & 0.999 & 25.76 & 4.12 & 0.884 & 10.96 & 10.98 & 0.980 \\
\hline \multicolumn{11}{|c|}{ Direct Blue 183} \\
\hline 20 & 22.54 & 0.13 & 0.13 & 0.992 & 7.93 & 2.45 & 0.999 & 1.65 & 7.67 & 0.94 \\
\hline 30 & 21.89 & 0.15 & 0.11 & 0.994 & 8.74 & 2.67 & 0.999 & 1.97 & 7.48 & 0.956 \\
\hline 40 & 21.65 & 0.17 & 0.10 & 0.995 & 9.67 & 2.87 & 0.999 & 2.65 & 7.23 & 0.945 \\
\hline 50 & 20.32 & 0.19 & 0.08 & 0.992 & 10.67 & 2.91 & 0.999 & 3.17 & 7.09 & 0.934 \\
\hline \multicolumn{11}{|c|}{ Direct Yellow 4} \\
\hline 20 & 20.54 & 0.12 & 0.12 & 0.991 & 7.91 & 2.43 & 0.991 & 1.69 & 7.66 & 0.956 \\
\hline 30 & 19.89 & 0.13 & 0.10 & 0.994 & 8.72 & 2.69 & 0.991 & 1.91 & 7.45 & 0.951 \\
\hline 40 & 18.65 & 0.15 & 0.09 & 0.993 & 9.66 & 2.89 & 0.992 & 2.56 & 7.29 & 0.949 \\
\hline 50 & 17.32 & 0.17 & 0.08 & 0.993 & 10.70 & 2.92 & 0.992 & 3.10 & 7.11 & 0.938 \\
\hline
\end{tabular}

Table 2: Correlation coefficients of isotherms adsorption of the three directs dyes.

\begin{tabular}{|c|c|c|c|c|c|c|c|c|c|c|}
\hline \multirow{2}{*}{ Dye Concentration (mg/L) } & \multirow{2}{*}{$\left(q_{e}\right)_{\exp }$} & \multirow{2}{*}{$\begin{array}{c}\text { Intraparticle diffusion } \\
\text { model }\end{array}$} & \multicolumn{5}{|c|}{$\begin{array}{l}\text { Pseudo-first } \\
\text { order }\end{array}$} & \multicolumn{3}{|c|}{ Pseudo-second order } \\
\hline & & & I & $\mathrm{R} 12$ & $\left(q_{\mathrm{e}}\right)_{\text {cal. }}$ & $k_{1}$ & $\mathbf{R}_{\mathrm{T}}^{2}$ & $\left(q_{e}\right)_{\text {cal. }}$ & $k_{2}$ & $\mathbf{R}_{\mathrm{T}}^{2}$ \\
\hline \multicolumn{11}{|l|}{ Direct Red 216} \\
\hline 20 & 23.07 & 4.53 & 6.12 & 0.68 & 09.25 & 0.27 & 0.48 & 24.07 & 0.045 & 0.99 \\
\hline 40 & 42.45 & 7.07 & 13.00 & 0.79 & 22.55 & 0.38 & 0.61 & 45.76 & 0.03 & 0.98 \\
\hline 60 & 54.47 & 8.82 & 14.01 & 0.86 & 39.01 & 0.39 & 0.86 & 61.56 & 0.02 & 0.99 \\
\hline 80 & 59.55 & 8.01 & 15.66 & 0.91 & 42.31 & 0.42 & 0.79 & 77.81 & 0.15 & 0.99 \\
\hline 100 & 65.78 & 9.93 & 16.45 & 0.92 & 45.76 & 0.45 & 0.68 & 99.78 & 0.01 & 0.99 \\
\hline \multicolumn{11}{|l|}{ Direct Blue 183} \\
\hline 20 & 21.56 & 2.74 & 7.16 & 0.64 & 11.54 & 0.92 & 0.95 & 19.67 & 0.05 & 0.99 \\
\hline 40 & 40.32 & 6.65 & 13.88 & 0.68 & 18.79 & 0.68 & 0.94 & 37.45 & 0.03 & 0.98 \\
\hline 60 & 49.83 & 7.78 & 14.32 & 0.73 & 22.78 & 0.62 & 0.92 & 42.78 & 0.02 & 0.99 \\
\hline 80 & 56.13 & 8.11 & 14.99 & 0.76 & 23.10 & 0.59 & 0.91 & 48.65 & & 0.99 \\
\hline 100 & 63.78 & 8.86 & 15.65 & 0.80 & 35.76 & 0.56 & 0.90 & 56.35 & 0.02 & 0.99 \\
\hline \multicolumn{11}{|l|}{ Direct Yellow 4} \\
\hline 20 & 20.25 & 2.74 & 7.66 & 0.64 & 11.45 & 0.94 & 0.94 & 21.67 & 0.06 & 0.99 \\
\hline 40 & 38.23 & 5.65 & 13.25 & 0.69 & 17.79 & 0.74 & 0.95 & 31.74 & 0.04 & 0.99 \\
\hline 60 & 47.90 & 6.21 & 14.78 & 0.73 & 21.78 & 0.65 & 0.95 & 40.78 & 0.039 & 0.98 \\
\hline 80 & 58.62 & 7.10 & 15.06 & 0.77 & 22.56 & 0.61 & 0.94 & 51.65 & 0.03 & 0.98 \\
\hline 100 & 61.80 & 7.42 & 15.66 & 0.80 & 35.76 & 0.57 & 0.93 & 60.88 & 0.02 & 0.99 \\
\hline
\end{tabular}

Table 3: Parameters of adsorption energy for the three directs dyes.

of the equation of the pseudo-second order, the integration of Equation (4) give Equation (5):

$$
\frac{t}{q_{t}}=\frac{1}{k_{2}} \frac{1}{q_{c}^{2}}+\frac{1}{q_{c}} t
$$

(Equation 5)

The adsorption model of the three dyes studied is consistent with pseudo-second order adsorption kinetics with a good correlation coefficient.

Freundlich Langmuir and Tempkin models studied the models of adsorption isotherms at equilibrium. The Langmuir equation is very suitable to describe the adsorption on materials on surfaces with homogeneous porosities. The Langmuir model is based on the following assumptions: energy adsorption sites uniformly, adsorption in monolayer (homogeneous porosities) without interaction between the molecules fixed on the pores. can be write a mathematical expression of the Langmuir model as [32]:

$$
q_{c}=\frac{Q_{c} \cdot K_{L} C_{e}}{1+k_{e} C_{2}}
$$


Citation: Ouslimani N, Boureghda MZM (2018) Removal of Directs Dyes from Wastewater by Cotton Fiber Waste. Int J Waste Resour 8: 330 . doi:

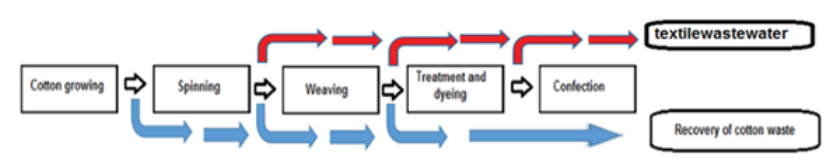

Figure 4: Microscopic view of the cotton production line.

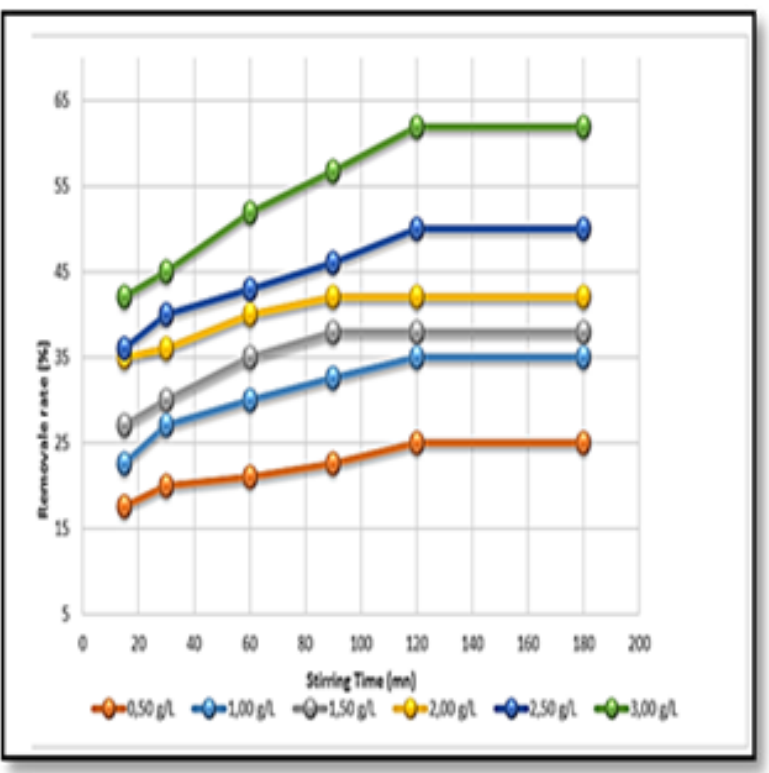

Figure 5: Influence of contact time and the fiber mass on the rate of discoloration (blue direct dye).

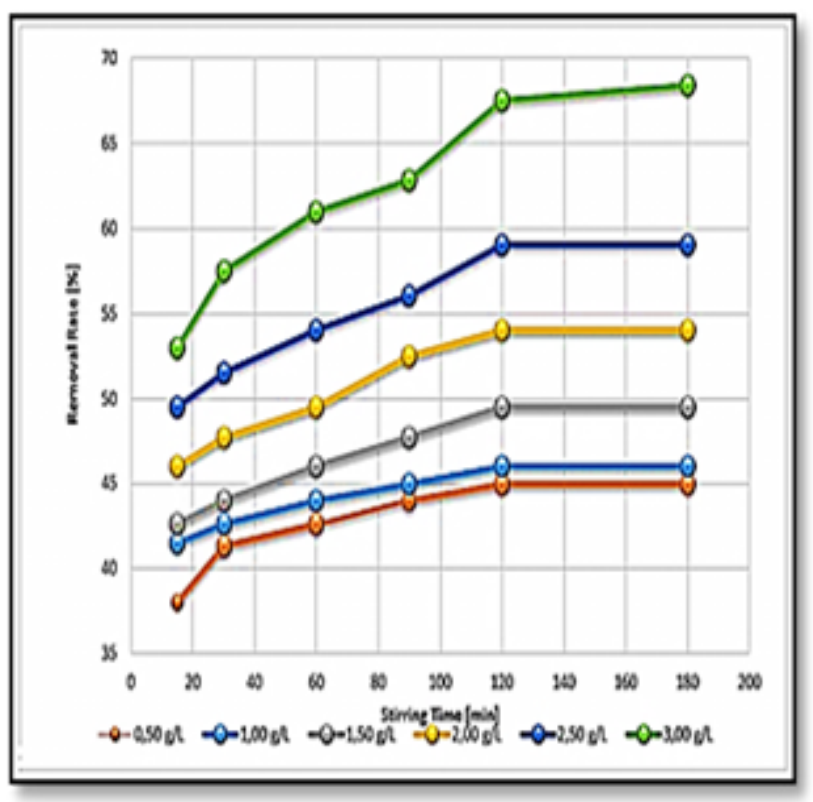

Figure 6: Influence of contact time and the fiber mass on the rate of discoloration (red direct dye).

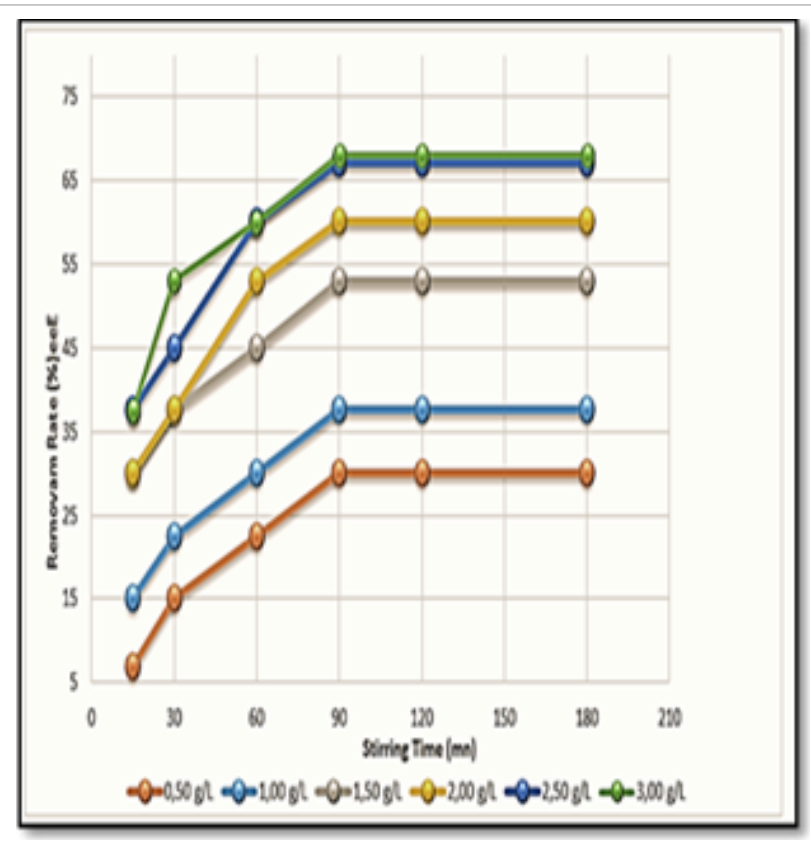

Figure 7: Influence of contact time and the fiber mass on the rate of discoloration (yellow direct dye).

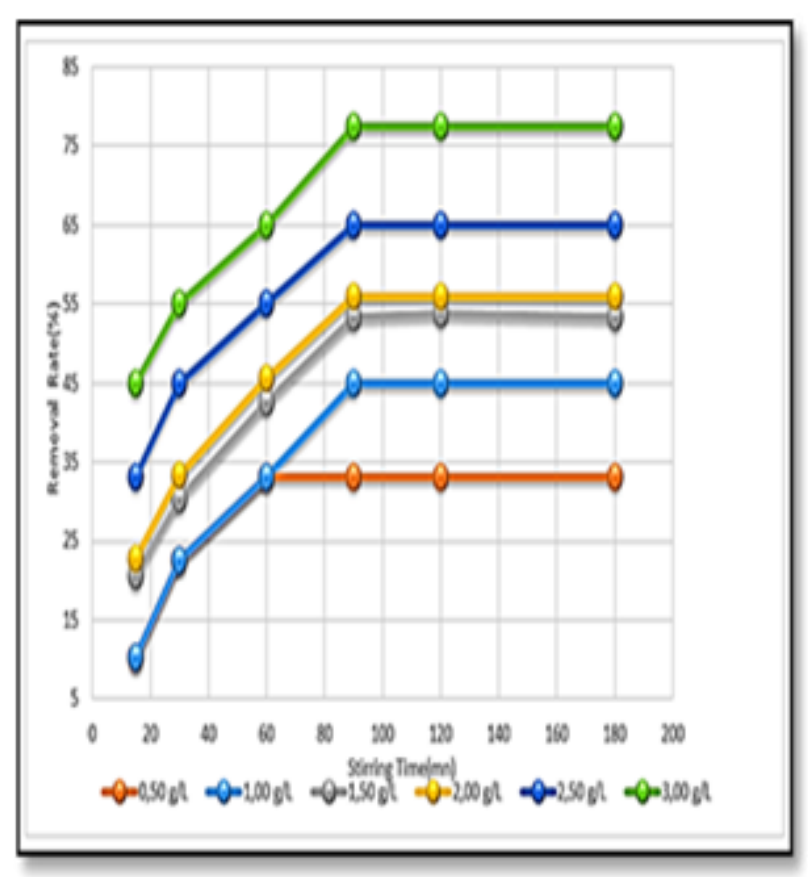

Figure 8: Influence of contact time and the fiber mass on the rate of discoloration (blue direct dye).

If $\mathrm{K}_{\mathrm{L}}$ is Langmuir equilibrium constant $(\mathrm{L} / \mathrm{mg}), \mathrm{C}_{\mathrm{e}}$ is the equilibrium

concentration of the adsorbate $(\mathrm{mg} / \mathrm{L}) \mathrm{q}_{\mathrm{e}}(\mathrm{mg} / \mathrm{g})$ is the adsorbed quantity at equilibrium, and $\mathrm{Q}_{0}$ the maximum adsorption capacity $(\mathrm{mg} / \mathrm{g})$. The Langmuir linear equation is:

$$
\frac{\mathrm{C}_{\mathrm{e}}}{\mathrm{q}_{\mathrm{c}}}=\frac{1}{\mathrm{~K}_{\mathrm{L}}} \frac{1}{\mathrm{Q}_{0}}+\frac{\mathrm{C}_{\mathrm{e}}}{\mathrm{Q}_{0}}
$$

(Equation 7) 
Citation: Ouslimani N, Boureghda MZM (2018) Removal of Directs Dyes from Wastewater by Cotton Fiber Waste. Int J Waste Resour 8: 330 . doi: 10.4172/2252-5211.1000330

Page 6 of 8

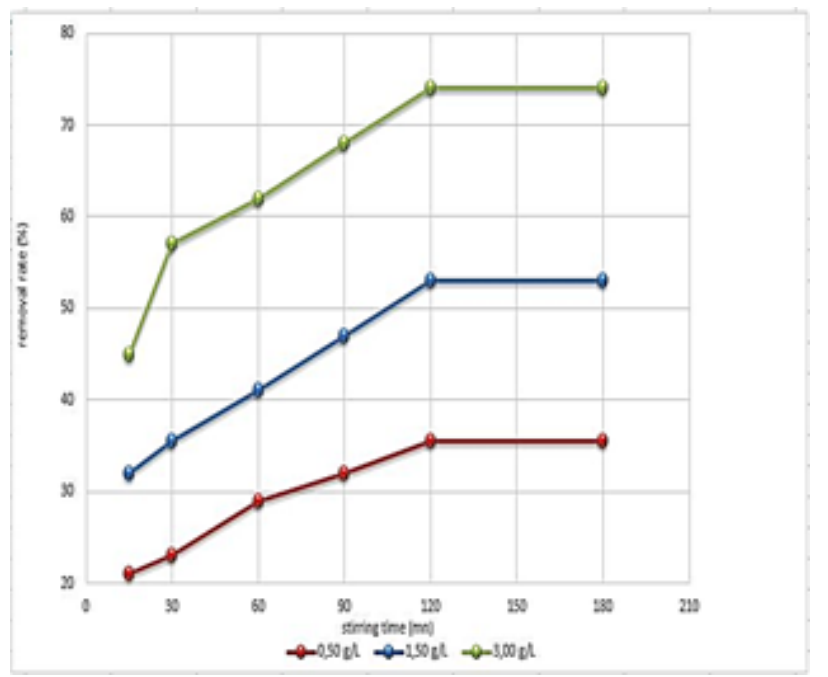

Figure 9: Influence of agitation time and the fiber mass on the rate of discoloration (red direct dye).

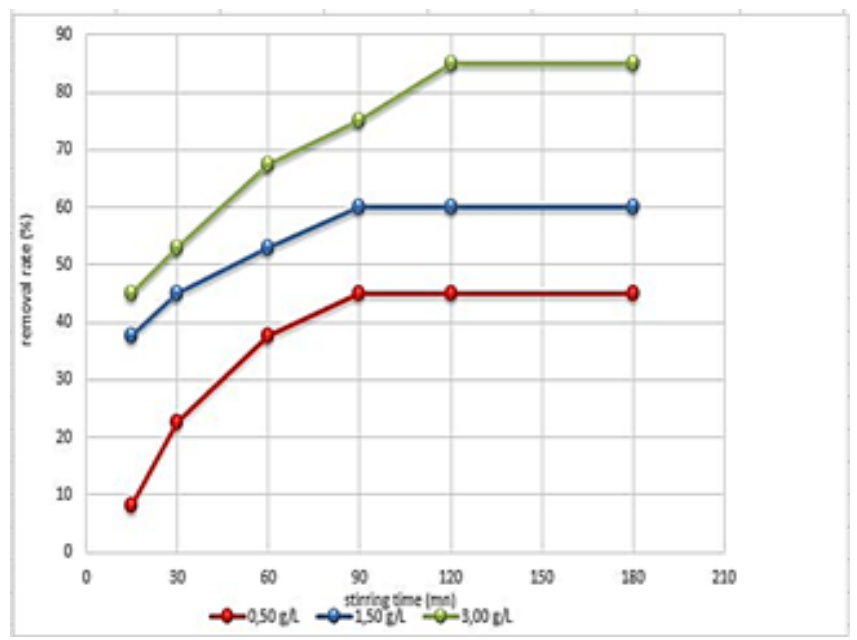

Figure 10: Influence of agitation time and the fiber mass on the rate of discoloration (blue direct).

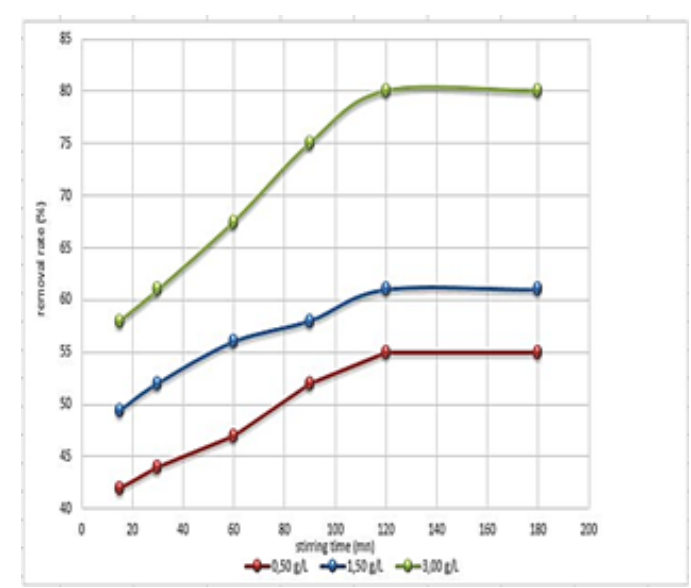

Figure 11: Influence of agitation time and the fiber mass on the rate of discoloration (yellow direct dye).
The essential characteristic of Langmuir isotherm can be expressed

by the dimensionless constant called equilibrium parameter, $\mathrm{R}_{\mathrm{L}}$, defined by:

$$
R_{L}=\frac{1}{1+K_{L}+C_{0}}
$$

Where $\mathrm{C}_{0}$ is the initial dye concentration $(\mathrm{mg} / \mathrm{L}) . \mathrm{R}_{\mathrm{L}}$ values indicate the type of isotherm to be irreversible $\left(R_{L}=0\right)$, favorable $\left(0<R_{L}<1\right)$, and unfavorable $\left(\mathrm{R}_{\mathrm{L}}>1\right)$ [33].

The Freundlich isotherm shows the heterogeneity of the surface of the adsorbate (cotton) and indisks that the adsorption occurs at sites having different adsorption energies and different diameters distributed unequally on the surface. The adsorption energy varies as a function of the surface coverage. A mathematical expression of the Freundlich isotherm is:

$$
q_{e}=K_{F} C_{e}^{1 / n}
$$

If $\mathrm{n}$ is the heterogeneity factor and $\mathrm{K}_{\mathrm{F}}(\mathrm{L} / \mathrm{mg})$ is constant Freundlich, $\mathrm{K}_{\mathrm{F}}$ will be the value is related to the adsorption performance, while the value " 1 / $\mathrm{n}$ " is a function of the intensity of 'adsorption.

Values " $1 / \mathrm{n}$ " direct us to the type of isothermal irreversible if (1 / $\mathrm{n}=0)$, positive $(0<1 / \mathrm{n}<1)$, negative $(1 / \mathrm{n}>1)$. Equation (9) can be reduced to the linear form [33]:

$$
\log q_{e}=\log K_{F}+\frac{1}{n} \log C_{e}
$$

(Equation 10)

The Tempkin model of isotherm is function of a factor that specifically takes into account the adsorbats species with adsorbent interactions. The Tempkin equation is given as [34,35]:

$$
q_{c}=\frac{R T}{b \operatorname{Ln}\left(K_{T} C_{e}\right)}
$$

(Equation 11)

This can be linearized as:

$$
q_{e}=B_{1} \operatorname{Ln} K_{T}+B_{1} \operatorname{Ln} C_{e}
$$

Where:

$$
B_{1}=\frac{R T}{b}
$$

The Tempkin [34] equation is based on two hypotheses, the first being that the adsorption energy of the dye molecules in the boundary layer decreases proportionally with the degree of accumulation of these molecules following adsorbent "fixation" models. adsorbate "and secondly, that the adsorption is characterized by a uniform distribution of the maximum binding energies. by plotting a curve of " $\mathrm{q}_{e}$ " with respect to "ln $\mathrm{C}_{e}$ ", it will appear the isothermal constants, $\mathrm{B}_{1}$ (the slope) and $\mathrm{K}_{\mathrm{T}}$ (the ordinate at the origin). $\mathrm{K}_{\mathrm{T}}$ being the equilibrium binding constant $(\mathrm{L} / \mathrm{mol}$ ) corresponding to the maximum binding energy and the constant $\mathrm{B} 1$ is related to the adsorption energy. $\mathrm{Q}_{0}, \mathrm{~K}_{\mathrm{L}}, \mathrm{R}_{\mathrm{L}}, \mathrm{R}_{i}^{\mathrm{i}}$ Langmuir isothermal correlation coefficients), $\mathrm{K}_{\mathrm{F}} \mathrm{n}, R_{F}^{2}$ (Freundlich isothermal correlation coefficients), $\mathrm{KT}, \mathrm{B} 1$ and $R_{T}^{2}$ of the isothermal isotherm).

The values Found show that the isotherms of Direct Red and Direct 


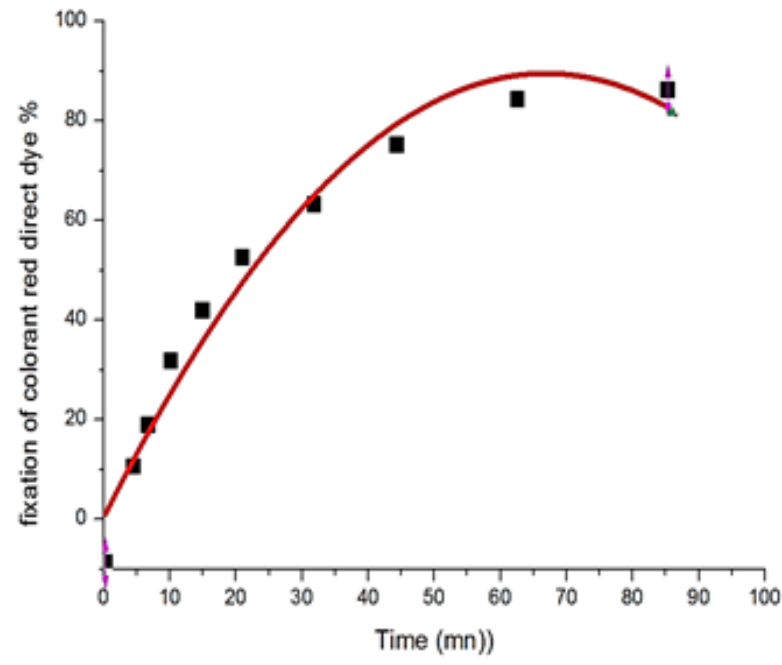

Figure 12: Kinetics of fixation of blue dye.

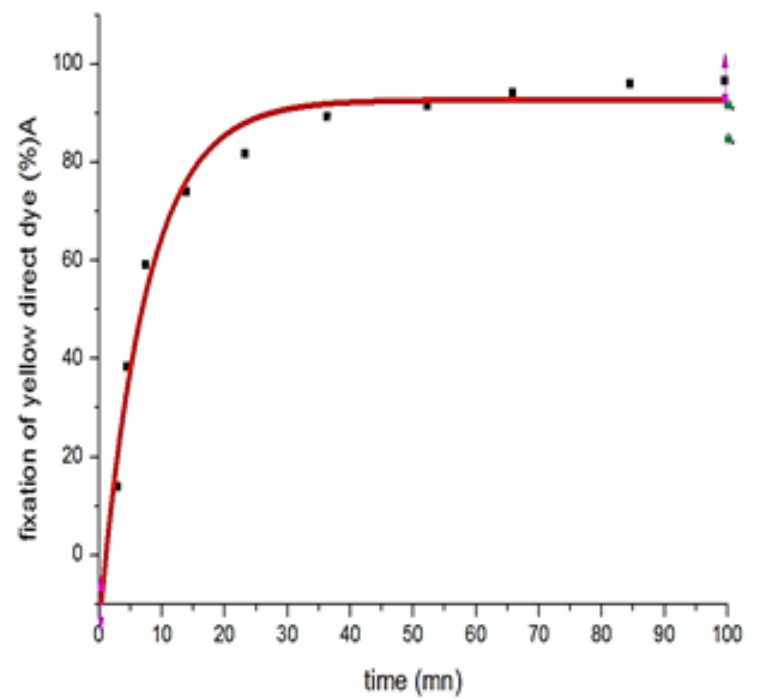

Figure 13: Kinetics of fixation of red dye.

Blue follow the Langmuir isotherms while insulated from direct yellow follow the model Freundlich [36].

\section{Determination of the dye exhaustion}

Rate of the dyeing time: Dyeing time is the time taken by the system in a dyeing process to absorb the maximum amount of equilibrium dye. This value will allow us to compare the kinetics of rise of three dyes used on cotton fiber nonwoven, are shown in Figures 12-14.

This approach can be explained by the influence of the chemical spatial structure of the dye, and its size, which have a direct influence on the mode of fixation of the dye molecule on the fiber characterized mainly by its porosity and the homogeneity of its adsorbent surface., it appears that the adsorption of the blue dye is monolayer and its fixation is flat, while for the other two dyes, the trend of the curve proves a progressive and slow fixation, this is due to the structures of the dye

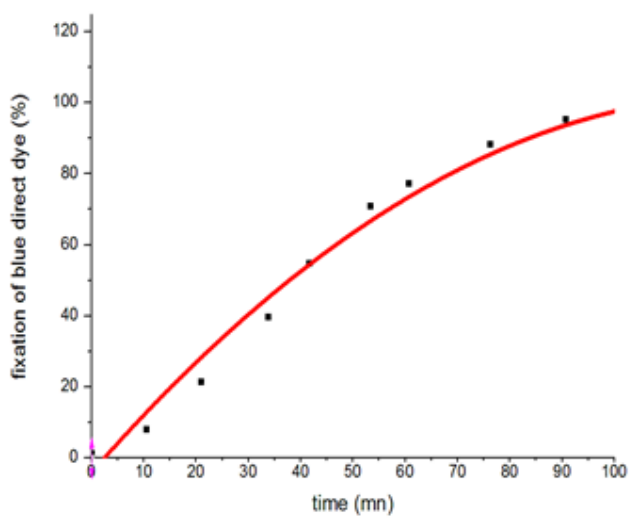

Figure 14: Kinetics of fixation of yellow dye.

molecules and to their mode of attachment to the surface of the cotton fiber [37].

\section{Conclusion}

Direct dyes, very soluble, are also toxic and mutagenic for the environment to eliminate these defects, several methods of bleaching textiles have been implemented, which argues in favor of their adsorption recovery on waste cotton fibers on site, at very low cost of treatment; This is why we recommend the use of the "adsorption" method by using fibrous textile waste in this plant. This method has the advantage of being less expensive and valuable for waste and allows an effective treatment of the water of dyeing, there is a very high abbey of the parameters of pollution of the treated water.

Finally, it is found that the bleaching speed is proportional to the fibrous mass and agitation, which positively influences the bleaching performance.

\section{Acknowledgment}

The authors would like to place on record their sincere thanks to the textile manufactory of Draa-Benkhedda for the financial assistance, and "Unit of research: Materials- Proceeding et Environment" (UR-MPE) of Boumerdes university, for its scientific assistance in the realization of this work.

\section{References}

1. El-Sharkawy EA (2001) Adsorption of textile dyes on to activated carbons synthesized from solid waste: Decolourizing power in relation to surface properties. Sci Technol 19: 795-811.

2. Aboua KN, Yobouet YA, Yao KB, Goné DL, Trokourey A (2015) Investigation of dye adsorption onto activated carbon from the shells of Macoré fruit. J Environ Manage 1: 156:10-14.

3. Elmoubarki R, Mahjoubi FZ, Tounsadi H, Moustadraf J, Abdennouri M, et al. (2015) Adsorption of textile dyes on raw and decanted Moroccan clays: Kinetics, equilibrium and thermodynamics. Water Resources and Industry 9: 16-29.

4. Chibane M, Zerbet M, Carja G, Sinan F (2012) Application of low-cost adsorbents for arsenic removal: A review. J Environ Chem Ecotoxicol 4: 91-102.

5. Ramesh BB, Parande AK, Raghu S, Kumar T (2007) Waste generation and effluent treatment. J Cotton Sci 11: 141-153.

6. Zarezadeh- Mehrizi M, Badiei A (2014) Highly efficient removal of basic blue 41 with nanoporous silica. Water Resources and Industry 5: 49-57.

7. Buthelezi SP, Olaniran AO, Pillay B (2012) Textile dye removal from wastewater effluents using bioflocculants produced by indigenous bacterial isolates. Molecules 17: 14260-14274.

8. Lin SH, Chen LM (1997) Treatment of textile waste waters by chemical methods for reuse. Water Res 31: 868-876. 
Citation: Ouslimani N, Boureghda MZM (2018) Removal of Directs Dyes from Wastewater by Cotton Fiber Waste. Int J Waste Resour 8: 330 . doi: $10.4172 / 2252-5211.1000330$

Page 8 of 8

9. Gürses A, Açıkyıldız M, Güneş K, Sadi Gürses M (2016) Dyes and pigments: Their structure and properties. Dyes and Pigments, pp: 13-29.

10. Zheng C, Zhao L, Zhou X, Fu Z, Li A (2013) Treatment technologies for organic wastewater, water treatment. InTech.

11. Nagarethinam K, Mariappan M (2002) Adsorption of Congo red on various activated carbons: A comparative study. Water Air Soil Pollut 1: 289-305.

12. Ben Mansour H, Boughzala O, Dridi D, Barillier D, Chekir Ghedira L Mosrati R (2011) Les colorants textiles sources de contamination de l'eau : CRIBLAGE de la toxicité et des méthodes de traitement, revue sciences de l'eau 24: 209-238.

13. Hourlier F, Massé A, Jaouen P, Lakel A, Gérente C, et al. (2010) Formulation of a synthetic greywater as an evaluation tool for wastewater recycling technologies. Environ Technol 31: 215-223.

14. Manjushree C, Mostafa MG, Biswas TK, Saha AK (2013) Treatment of leather industrial effluents by filtration and coagulation processes. Water Resources and Industry 3: 11-22.

15. Coia - Ahlman S, Groff KA (1990) Textile wastes. J Wat Poll Cont Fed 62 473-478.

16. Zhang MM, Chen WM, Chen BY, Chang CT, Hsueh CC, et al. (2010) Comparative study on characteristics of azo dye depolarization by indigenous ecolorizers. Bioresour Technol 10: 2651-2656.

17. Walton KS, Cavalcante CL, Jr Douglas M, LeVan (2006) Adsorption of light alkanes on coconut nanoporous activated carbon, thermodynamics and separation processes. Braz J Chem 23: 555-561.

18. McKay G (1983) The adsorption of dyestuff from aqueous solution using activated carbon: analytical solution for batch adsorption based on external mass transfer and pore diffusion. Biochem Eng J 27: 187-194.

19. Lin SH, Peng CF (1994) Treatment of textile wastewater by electrochemical method. Water Res 28: 277-282.

20. Li J, Li M, Li J, Sun H (2007) Decolourization of azo dye direct scarlet 4BS solution using exfoliated graphite under ultrasonic irradiation. Ultrason Sonochem 14: 241-249.

21. Lepot $L$ (2012) Application, de la spectropie Raman a l'analyse des colorants sur fibres de coton dans le contexte de la criminalistique, dissertation présentée en vue de l'obtention du grade de docteur en sciences. Université de Liège.

22. Sanghi R, Bhattacharya B (2002) Review on decolorisation of aqueous dye solutions by low cost adsorbents, Coloration Technology. Society of Dyes and Colorants 118: 256-269.
23. Miljkovic N, Ignjatovic B, Aleksandra R, Zarubica (2007) Influence of different parameters on dyeing of knitting material with reactive dyes. Facta universitatis, Series: Physics, Chemistry and Technology 5: 69-84

24. Gregg I, Sing KS, Sing W (1982) The physical adsorption of gases by nonporous solids, the type II isotherm in adsorption surface area and porosity. Academic Press, London. pp: 41-110

25. Kaewprasit E, Hequet N, Abidi F, Kaewprasit C (1998) Application of methylene Blue adsorption to cotton fiber specific surface area measurement: Part I. Methodology. J Cotton Sci 2: 164-173.

26. Sharmila J (2010) The impact of textile dyes on the biochemistry and histology of a freshwater fish, tilapia, Oreochromis mossambicus. Thesis, Education and Research Institute University.

27. Verma $Y$ (2008) Acute toxicity assessment of textile dyes and textile and dye industrial effluents using Daphnia magna bioassay. Toxicology Ind Heath 24 491-500.

28. Hildebrand S, Schmah IR, Wodarz R, Kimme IP, Dartsch C (1999) Azo dyes and carcinogenic aromatic amines in cell cultures. Int Arch Occup Environ Health 72: M52-M56.

29. Ho YS, Chiang CC (2001) Sorption studies of acid dye by mixed sorbents Adsorption 7: 139-147.

30. Weber WJ (1963) Adsorption on carbon from solutions. Journal of the Sanitary Engineering Division ASCE 89: 3-60.

31. Lagergren S (1898) About the theory of so-called adsorption of soluble substances. Scientific Research 24: 1-39.

32. Langmuir (1918) The adsorption of gases on plane surfaces of glass, mica and platinum. J Am Chem Soc 40: 1361-1403.

33. Mahmoudi MN, Mokhtar A (2008) Modelling and sensitivity analysis of dyes adsorption onto natural adsorbent from colored textile wastewater. J Appl Polym Sci 109: 4043-4048.

34. Tempkin MJ, Pyzhev-Recent V (1940) Modification to langmuir isotherms. Acta Physicochim USSR 12: 217-222.

35. Kim Y, Kim C, Choi I, Rengaraj S, Yi J (2004) Arsenic removal using mesoporous alumina prepared via a templating method. Environ Sci Technol 38: 924-931.

36. Freundlich HMF (1906) Uber die adsorption in lasugen, Zeitschrift fur Physikalische Chemie. Leipzig 57A: 385-470.

37. Zhao HZ, Sun Y, Xu LN, Ni JR (2010) Removal of acid orange 7 in simulated wastewater using a three-dimensional electrode reactor: Removal mechanisms and dye degradation pathway. Chemosphere 78: 46-51. 